\title{
Educación Popular e Interculturalidad en Haití
}

\author{
Popular Education and Interculturality in Haiti
}

\author{
Educação Popular e Interculturalidade no Haiti
}

\author{
Nicolás Iglesias Mills \\ Candidato a magister en educación, mención política y gestión \\ Estudiante Universidad Austral de Chile \\ nicolasimuy@gmail.com
}

\section{Resumen}

La realidad histórica de Haití nos enfrenta constantemente a un debate filosófico y antropológico de nuestro vínculo con los demás y de cómo se organizan las relaciones de poder a través de una supuesta asistencia humanitaria, que muchas veces se ha transformado en evidencia de que la lógica fraterna del ser humano todavía tiene mucho camino que andar.

En Haití, la educación popular, que genera propuestas transformadoras desde una horizontalidad, es casi obligatoria, pero sobre todo provocadora. Lo mismo pasa con una necesaria interculturalidad que incita al que viene de fuera a dejarse afectar, transformar su vida y así transformar el continente según los parámetros que una vez pensó que quería o podía cambiar.

Palabras Claves: Educación popular, interculturalidad, Haití, epistemología, cooperación internacional.

\begin{abstract}
Haiti's historical reality put us in a constant philosophical and anthropological debate, about our connections with others and how power relationships are organized, sometimes through a so-called humanitarian assistance, that many times have transformed itself in evidence of the process that's left in the fraternal logic of the human being. In Haiti, popular education, that create transforming proposal through a horizontality, it's almost mandatory, but especially, provocative. Same thing happens with intercultural relations, because it incites the one that comes from outside to let himself affected, transform his/her life, so this way he can transform a hole continent according the same settings he had thought to change.
\end{abstract}


Keywords: Popular egucation, interculturality, haiti, epistemology, international cooperation.

\section{Resumo}

A realidade histórica do Haiti nos confronta constantemente com um debate filosófico e antropológico sobre nosso relacionamento com os outros e como as relações de poder são organizadas através de uma suposta ajuda humanitária, que muitas vezes se transformou em evidência de que a lógica fraterna do ser humano ainda tem um longo caminho a percorrer. No Haiti, a educação popular, que gera propostas transformadoras sob uma perspectiva horizontal, é quase obrigatória, más sobretudo provocadora. O mesmo acontece com uma interculturalidade necessária que incentiva aqueles que vêm de fora para se deixarem afetar, transformar suas vidas e transformar o continente de acordo com os parâmetros que eles pensaram que queriam ou poderiam mudar.

\section{Palavras-chave: educação popular, interculturalidade, Haiti, epistemologia, cooperação internacional.}

\section{Introducción}

Cuando empecé mi carrera universitaria, no sabía exactamente por qué me quería dedicar a la primera infancia. Muchos manifestaron sus temores, siendo yo hombre en una carrera donde el género femenino es casi totalitario. Los temores de todos eran fundamentados, porque el paso que acababa de dar iba en contra a muchas verdades establecidas, estaba siguiendo el camino de la mentira.

Empecé a entender mi vocación el día que inicié mis prácticas, y terminé por confirmarlas el día que miré a los ojos a un niño de 1 año en situación de abandono y pobreza. Su educadora dijo que estaba allí porque fue el trabajo que consiguió, y que no lo podía mirar a los ojos porque ese había sido su mecanismo para no sufrir tanto ante la miseria ajena. Estuve ahí varios meses y nuestra relación creció y juntos tuvimos un progreso donde él se desarrollaba más en lo motor, y yo en la comprensión del ser humano. Este niño y yo, aunque viniéramos de situaciones muy lejanas, compartíamos algo: íbamos en el camino que otros decían que no podíamos atravesar. La diferencia es que mi camino yo lo elegí y a él no le quedaba otra opción.

Las verdades y las mentiras siempre vienen juntas, y este trabajo trata de entender que, desde el camino de la mentira, de la exclusión, se puede abrazar al resto. Las diferentes verdades excluyentes tienen que encontrarse, y proponemos que este camino sea desde la relación intercultural que se sugiere como estrategia en la educación popular, aquella que tiene como objetivo el cambio y la transformación desde los de más abajo, desde los protagonistas de la misma educación, quienes sean ellos que sean.

En este caso analizamos en concreto el caso haitiano ya que, a nuestro parecer, representa un terreno que posee las características históricas y culturales para generar propuestas efectivas de educación popular e interculturalidad. Intentaremos probar que el territorio haitiano, desde 
una perspectiva histórica, va generando tierra fértil para la educación popular y el trabajo de la interculturalidad en ella.

Teorías, reflexión e historia se van uniendo durante todo el texto para articularse en la educación popular y la interculturalidad.

\section{Verdades, mentiras, exclusiones e inclusiones}

"Los españoles describieron a los taínos como pacíficos, mansos y saludables. En sus memorias, Colón escribió que 'todos estaban bien formados, con magníficos cuerpos y caras hermosas. No portaban armas, ni saben de ellas. Serán buenos sirvientes, y cristianos, porque me parecieron que no tenían religión. Traeré media docena de ellos a Sus Majestades para que aprendan a hablar' (...) Los españoles encontraron una resistencia masiva por parte de los habitantes de la isla, lo cual estableció un patrón para futuros encuentros en Haití entre los europeos y los africanos (...). El último aliento de la resistencia amerindia lo dirigió el hijo de Anacaona [poetisa y guerrera taína], Enriquillo, un cacique que huyó a las montañas de Bahoruco con esclavos africanos recién llegados, después de haber sido esclavizado, y su esposa violada y obligada a convertirse al cristianismo. Sus refugios de guerrilleros se llamaban palenques. Al final de la lucha apenas habían sobrevivido quinientos rebeldes, pero España se vio obligada a reconocer su 'independencia' en 1533 por medio de un tratado. El precio del tratado fue la mutilación y muerte de muchos de los cimarrones, los esclavos africanos fugitivos que se habían unido al movimiento de resistencia" (Bellegrade, P. 2004.).
Desde una perspectiva histórica Haití se ha conformado a partir de las constantes relaciones interculturales y multiculturales, para unos denominadas cooperación, para otros invasión, y para otras construcción común. Es importante aclarar que la multiculturalidad no es lo mismo que interculturalidad. La migración y la imposición de verdades instauran en general relaciones multiculturales, puesto que implica que diferentes culturas y verdades convivan en un mismo territorio sin tocarse (Alsina, R. 1999). Carrasco (2015) entiende la interculturalidad de 4 maneras: una característica propia de la cultura con elementos principales $\mathrm{y}$ secundarios; un elemento subjetivo e interpretativo para con el otro que es diferente; elementos propios de las culturas indígenas que surgen para revitalizar la costumbre que ha sido oprimida con anterioridad; y por último, la que tomamos para este trabajo, como elemento conformador de comunidades y grupos, es decir, como una estrategia propia de relación entre personas para generar elementos nuevos de convivencia y entendimiento. Como veremos más adelante, este último punto se relaciona directamente con la idea de la educación popular que entiende un relacionamiento horizontal de los actores protagonistas de la educación, retomando las diversidades que hay entre ellos y las diferentes culturas de fondo que pueden generar una negociación cultural.

Empezando por la colonia francesa, podemos ver que dichas relaciones han tomado diferentes formas: políticas, económicas, religiosas, culturales e ideológicas. La colonia francesa, las fuerzas armadas de Estados Unidos y el ejército de la ONU y el manejo de estadounidense de las elecciones democráticas ha representado la parte 
política de la invasión. La constante importación de productos extranjeros más baratos que los nacionales representa la parte económica. La represión de las iglesias cristianas más extremas para la eliminación del vudú (la religión tradicional del pueblo haitiano) representan la parte religiosa y cultural ya que esta idea conlleva en sí mismo las expresiones culturales más auténticas de la raíz del pueblo haitiano, como son la música, la pintura y la literatura que responden a este tipo de creencias. Existe una parte de la iglesia Católica vinculada y respetuosa con esta religión, aunque hay muchas iglesias cristianas extremas que se centran en un discurso moral que condena de sus tradiciones. Y por último la cooperación internacional en todas sus formas (desde los organismos oficiales de cooperación de los gobiernos hasta las constantes ong's que llegan al país bajo un manto de bondad), representan la parte ideológica de estas relaciones, puesto que todos estos son agentes externos.

El pueblo haitiano constantemente se ha encontrado reflexionando sobre por qué una verdad es superior a otra, por qué otra verdad es superior a la de sí mismos.

La verdad, que algunos llaman divina y otros un triste enfrentamiento realista con el mundo, no sería nada sin otra palabra llamada mentira. Porque a la hora de decir "esta es la verdad" dejamos afuera necesariamente otras ideas, llamadas mentiras. Por ende, necesariamente la verdad excluye. La verdad o la mentira en sí mismas no tienen un valor ético, lo tiene la acción de incluir o excluir, lo tiene en cuanto asume un acto político intrínseco (Dussel, 2007).

Vargas Llosa, hablando de la veracidad de sus novelas nos explica que el sólo hecho de que el autor se vea forzado a elegir determinadas palabras para traducir lo que quiere expresar, hace que "el novelista privilegie una y asesina otras mil posibilidades o versiones de aquello que describe" (Vargas Llosa, M. 1990).

¿Qué es la verdad sino un conjunto de consensos acordados por un grupo de personas? No podemos juzgar la verdad en sí, sino a qué nos lleva esta. Expliquemos mejor esta idea. Si mentimos lo suficientemente bien durante un período determinado de tiempo, quizá una posible mentira se convierta en verdad para algunos, o para uno mismo. Esta idea se convierte en verdad inmediatamente al ser creída por un grupo. A esto a veces se le puede llamar paradigma, término acuñado por Kuhn en 1962.

Podemos decir que nosotros nos creemos nuestras verdades, pero las verdades más fuertes se crean en una relación, por eso, no hay mentiras ni verdades buenas, sino incluyentes o excluyentes. Se podría debatir en este punto si existen verdaderamente verdades incluyentes. Ya definimos por qué son excluyentes, pero es necesario entender que las verdades más incluyentes se terminan transformando en paradigmas, y muchas veces estos son los más excluyentes. Queda evidenciado cuando profundizamos, por ejemplo, en el concepto de "sur". Este fue abordado por diversos autores como Boaventura do Souza Santos (2014) o Enrique Dussel (2015) como metáfora de aquel espacio (no tanto geográfico como metafórico) en el cual se encuentran aquellos grupos con poca o nada influencia dentro de un panorama social más grande, o aquellos que han sido oprimidos por un poder mayor. El pintor Joaquín Torres García realizó un retrato acertado de la idea de sur en su cuadro "América dibujo: tinta 
sobre papel" (1946), el cual representa un mapa de América del Sur dado vuelta. El autor expone sobre esto:

"He dicho Escuela del Sur; porque en realidad, nuestro norte es el Sur. No debe haber norte, para nosotros, sino por oposición a nuestro Sur. Por eso ahora ponemos el mapa al revés, y entonces ya tenemos justa idea de nuestra posición, y no como quieren en el resto del mundo. La punta de América, desde ahora, prolongándose, señala insistentemente el Sur, nuestro norte." (Torres García, J. 1941).

Con esta frase e imagen recordamos lo fácil que debe de ser pasar del sur al norte, de oprimido a opresor, de seguir excluyendo con verdades impuestas no importa por quién. Reafirmamos la alerta con la idea de Meszaros (2008) sobre las hegemonías políticas:

"El proyecto socialista triunfará solo si se lo presenta y reivindica como alternativa hegemónica al metabolismo social dominante al nivel estructural capitalista" (Meszaros, I. 2008 p. 86).

Esto no se trata de estar bien con Dios y con el Diablo, simplemente de entender lo difícil que es profundizar en el espíritu fraternal del ser humano. Humberto Maturana (1999) expone que biológicamente somos seres cooperativos, aunque nos hemos empecinado en desarrollarnos con base a la negación del otro. Solemos pensar que nos hacemos nosotros si nos diferenciamos con el otro, pero se nos hace más difícil que somos nosotros en función de los demás y en la relación vincular que hay entre individuo y sociedad.

Por eso "la batalla por la injusticia social global debe, por tanto, ser también una batalla por la justicia cognitiva global" (de Souza Santos, B. 2014). La noción de verdad conlleva dentro un fuerte concepto de poder. Aquel que se las ingenie para dominar de una $\mathrm{u}$ otra forma podrá "imponer" su verdad. Aunque hay otras opciones y ejemplos en el mundo, en la mayoría de las ocasiones la imposición de una verdad por sobre otra implica algún tipo de violencia, y cuando el poder se junta con la violencia es cuando hay una imposición. Esta noción viene del concepto de poder utilizado primero por la Escuela de Frankfurt (Palacio Díaz, A. 2005), y luego retomado por Paulo Freire (1968) en su famosa obra, la Pedagogía del Oprimido.

Podemos ver cómo en Haití las verdades más poderosas fueron vinculándose con el pueblo taíno/amerindio que se encontraba en la Isla de la Española, o más bien Kiskeya, como se llamaba en el período anterior a la colonia.

Los Taínos no tenían una buena relación con sus colonos. Primero a mano de los españoles, y luego a mano de los franceses, los Taínos se negaban al trabajo forzado que, bajo una bandera (verdad) de progreso y generosidad, sus colonos querían imponer. En el caso de Haití me cuesta mucho trabajo creer la idea de Franz Fanon (1961) donde "el colono y el colonizado se conocen desde hace mucho tiempo", puesto que los vínculos reales entre colono y colonizado casi no existían de este lado de la isla, que España cedió a Francia. Como se negaban profundamente a su propuesta de trabajo, los franceses les cortaban las manos y los pies, para luego echarlos a los perros. Por eso, bajo la venta de una verdad de tierras prometidas y libertad, se vieron en necesidad de traer esclavos de África. Aunque antes que nada pelearon juntos, el segundo vino a ocupar el lugar de oprimido, y el primero fue eliminado por 
no someterse a las verdades que traían los poderosos.

Años más tarde Haití es el primer país en independizarse en toda América Latina (1804) bajo manos de los propios esclavos, y eso seguro no ha quedado sin consecuencias.

"Haití es hoy el país más pobre del hemisferio occidental. Sin embargo, en la segunda mitad del siglo dieciocho producía más riqueza que cualquier otra colonia del mundo. En esta época, 50\% del comercio transatlántico de Francia se debía a Haití, y cerca del $20 \%$ de la población francesa dependía del comercio con Haití para su sustento" (Bellegrade, 2004).

La gran cantidad de riquezas que posee este país aún en el día de hoy no hicieron fácil la mantención de la independencia, ni externa ni internamente, aunque por la gran cantidad de opresiones que le siguieron la identidad del oprimido ha sido profundizada aún más.

No sólo en Haití, con el correr de los años hemos debatido el tema del otro. El otro ha sido mi hermano varias veces, pero el tema que nos ha movido siempre es el otro como diferente, como extraño, como el que viene de fuera.

Podemos trasladarnos inmediatamente a un pensamiento moderno, generado casi con el surgimiento de los Estados-Nación en la época de las colonias y el surgimiento del positivismo que sitúa a la ciencia como conocimiento universal superior, generando una exclusión a cualquier otro tipo de conocimiento. La historia haitiana nos recuerda, previamente, la postura de los europeos frente a los pueblos indígenas, convencidos de que su verdad era la verdad.

Europa se empieza a conformar frente a los demás, con un territorio concreto, en conjunto con el contacto con el indígena en América u otras civilizaciones. Para ellos entonces era necesario que los indígenas y los pueblos originarios empezaran a tomar el lugar de otro (el lugar de bárbaros poco ilustrados) para afirmarse como poseedores de la verdad y el conocimiento. No hay una cosa sin la otra. No hay yo sin tú.

\section{La identidad del oprimido: el ser más}

"Los primeros ocupantes de la isla, los españoles, abandonaron la parte occidental del territorio por no tener oro; los franceses que los reemplazaron encontraron "oro" en forma de esclavos y azúcar. De hecho, los esclavos y el azúcar fueron los principales recursos de Haití en la era colonial. Las corporaciones norteamericanas también encontraron 'oro' en la fuerza laboral haitiana, la peor pagada en la cuenca del Caribe. Realmente, la fuerza de trabajo barata es el recurso principal del moderno Haití, y en el sector industrial es femenina en su mayoría. La fuerza de trabajo barata de Haití y su proximidad geográfica al mercado de los Estados Unidos son grandes ventajas para las firmas norteamericanas. Para Haití, sin embargo, la combinación de fuerza de trabajo barata, el cambio del uso de la tierra y el aumento de la importación de los alimentos resultan depauperantes". (Bellegrade, P. 2004).

Es lógico pensar que ninguna persona se identificaría a sí mismo como oprimido o como opresor en primer lugar. Ningún niño nace sabiéndose en una relación de poder, o entendiendo que viene a un 
mundo construido por adultos donde poco tienen que decir y mucho para adaptarse. Lo mismo ha pasado en Haití, ningún haitiano ha nacido queriendo ser el objetivo del mundo para generar riquezas o inventar fórmulas nuevas de superación de la pobreza. Expliquemos mejor a qué nos referimos.

Lo que construye la identidad del oprimido es lo que Freire (1968) denomina "la vocación de ser más":

"La deshumanización, que no se verifica sólo en aquellos que fueron despojados de su humanidad sino también, aunque de manera diferente, en los que a ellos despojan, es distorsión de la vocación de SER MÁS. Es vocación posible en la historia, pero no es vocación histórica.

La violencia de los opresores, deshumanizándonos también, no instaura otra vocación, aquella de ser menos. Como distorsión del ser más, el ser menos conduce a los oprimidos, tarde o temprano, a luchar contra quién los minimizó. Lucha que sólo tiene sentido cuando los oprimidos, en la búsqueda por la recuperación de su humanidad, que deviene una forma de crearla, no se sienten idealistamente opresores de los opresores, ni se transforman, de hecho, en opresores de los opresores sino en restauradores de la humanidad de ambos." (Freire, P. 1968).

La identidad del oprimido tiene que ver necesariamente con una imposición de verdades que los excluye y que los invita a ser menos. Cuando se ocupa un lugar de excluido o de inferioridad es posible abrazar desde abajo a toda la humanidad. Por esto la identidad haitiana se fue creando con base y raíz en este abrazo desde abajo hacia arriba. Enrique Dussel (2007) hace alusión a este idea ${ }^{1}$, mencionando que la identidad de este continente acepta los retos, los integra y no se aterra por ellos, nos invita constantemente a ser más.

Anteriormente habíamos dicho que las ideas más inclusivas pueden ser las que más excluya, por eso debemos aclarar que no es que por ser más débil se tenga siempre la razón, sino que puede llegar a una consecuencia mucho más amplia e inclusiva, de aquellas verdades que incluyen más que excluyen (Todorov, T. 1986).

Boaventura de Souza Santos (2014) habla de llegar a una "ecología de saberes" desde el sur, y Leonardo Boff de que la escencia humana se encuentra en el cuidado de los demás. Todo esto es, en realidad, cómo construimos el mundo en relación con los otros, pero sobre todo desde dónde miramos.

"A principios del siglo veinte, Haití tuvo siete presidentes en siete años; la crisis culminó con la ocupación dictatorial del país entre 1915 y 1934 por el Cuerpo de Marines de los Estados Unidos. La etapa fue testigo de los inicios del 'fascismo haitiano'. Se impulsó la ley marcial durante todo el lapso que duró la ocupación, y se disolvió la Legislatura en 1917 - no se le volvió a convocar hasta 1930. En un período de seis meses, entre 1956 y 1957, hubo cinco gobiernos haitianos en rápida sucesión hasta que Estados Unidos ayudó a instalar la dictadura dinástica de Duvalier, la cual gobernó con puño de hierro hasta su

1 La palabra textual que utiliza este autor es "Hispanos", aunque me parecía un término un poco confuso como para utilizarlo aquí. 
derrocamiento en 1986". (Bellegrade, 2004).

La influencia norteamericana aún no cesa, y aunque los regímenes dictatoriales hayan concluido, la atribución intencional a la política haitiana sigue existiendo. La prueba de esto es la manipulación de las actuales elecciones en curso ${ }^{2}$.

Como consecuencia de una manipulación e inestabilidad política constante Haití ocupa desde hace ya mucho tiempo el lugar del país más pobre de América. En el año 2010 un terremoto arrasó con Haití dejando miles de muertos y heridos. La fama con la que ya contaba Haití se vio aumentada por millones de miradas del mundo entero que no entendían lo que estaba pasando y poco sabían de su historia. Entonces, la normalidad ya afianzada de la pobreza lastimosa comenzó a trabajar en diversos puntos del globo terráqueo.

En este punto debemos detenernos un poco porque se juega aquí las diferentes verdades acerca de lo que es la pobreza y cómo reaccionar ante ella. Debates como este han estado en boca de muchos, sobre todo desde la creación del Banco Mundial (1944) y la globalización de la pobreza. Uno de los ejemplos más claros es el del debate entre Peter Towsand y Amartya Sen, en 1985, con la incorporación de los

\footnotetext{
${ }^{2}$ Para profundizar en esta temática recomendamos el documento del estudio estadístico de las elecciones del 2015 por parte del instituto brasilero Igarapé se puede encontrar en el siguiente link: https://igarape.org.br/en/impact-of-electoral-fraud-onhaitian-voters-beliefs-about-democracy/ y el artículo sobre esta misma temática realizado en el 2016 por el sociólogo chileno Jorge Vásques, que se encuentra en la siguiente dirección: http://revistes.ub.edu/index.php/ACS/article/view/1600 6
}

conceptos de pobreza absoluta o pobreza relativa. Ambas son verdades que refieren a otros e imponen de a poco estilos de vivir una pobreza determinada. A pesar de estos debates a escala global, lo que más me preocupa es la manera de exteriorizar la pobreza y no hacernos responsables de ella. Cuantas más recetas tengamos para la superación de la pobreza, más nos alejamos de la misma y más van a ocupar un lugar de exclusión del sistema.

En el diseño de políticas públicas sociales para trabajar en contextos de pobreza nos atrevemos a meternos constantemente en sus casas, pero ¿quién dijo que podíamos meternos en las casas de otros estratos sociales ahora que entendemos que la pobreza y la desigualdad están altamente vinculadas?

La pobreza desde el punto de vista de oprimido nos vuelve a recordar la característica de "ser menos", acuñada por Freire y que ya explicamos con anterioridad. La pobreza que excluimos la dejamos en el menos, oprimida, quitándole de a poco la posibilidad de ser más.

Volviendo a Haití, la cooperación internacional ha funcionado como juzgado construyendo una verdad sobre la pobreza. Esta verdad incluye ideas sobre aquellos a "quienes debemos ir a ayudar" generando propuestas de concepción de la pobreza como un grupo aparte de la sociedad mundial que no puede valerse por sí misma. Esto lleva a un trabajo asistencialista con fórmules generalizables de erradicar la pobreza, como lo hizo el Banco Mundial asesorando diversas políticas sociales en el mundo (Mejía, MR. 2006). 
Debemos decir que Haití era ya un país invadido por las fuerzas armadas de las Naciones Unidas, bajo un concepto de una guerra inexistente, y es cuna de muchas ONG's y de la cooperación internacional en general. Es, probablemente, el país con más ONG's. Los propios haitianos denominan al país (en forma de ridiculizar a la cooperación internacional) como una Nación-ONG.

Con la constante influencia internacional, la noción de trabajar desde abajo ha impreso la identidad haitiana y caribeña en general. Esto, en la lógica del "ser más" de Freire, repiensa las lógicas de poder y revitaliza muchas veces las culturas de raíz que tienen los pueblos oprimidos, en este caso, la cultura vudú haitiana, tan reprimida por los grupos cristianos extremos que se han situado en la isla. ${ }^{3}$ Con fórmulas generalizables de erradicar la pobreza, como lo hizo el Banco Mundial asesorando diversas políticas sociales en el mundo (Mejía, MR. 2006).

Debemos decir que Haití era ya un país invadido por las fuerzas armadas de las Naciones Unidas, bajo un concepto de una guerra inexistente, y es cuna de muchas ONG's y de la cooperación internacional en general. Es, probablemente, el país con más ONG's. Los propios haitianos denominan al país (en forma de ridiculizar a la cooperación internacional) como una Nación-ONG.

Etnocentrismo, negritud o hispanos, son diferentes términos que se acuñaron para comprender la identidad del oprimido en

3 No queremos demonizar el asistencialismo por completo. Es cierto que en casos de pobreza extrema y en situaciones de verdadera urgencia, la asistencia es lo único que nos queda. este continente y en otros. Aimé Césaire comprende que existe una correlación de identidad entre los esclavos traídos del continente africano y los pueblos originarios de américa. Lo existiría también con otros grupos: las personas en situación de pobreza, los enfermos mentales, las religiones minoritarias, los migrantes y refugiados, entre otros. Simplemente no entran dentro de una verdad cada vez más excluyente.

"Para el martiniqueño, la negritud no sólo implica la valorización de la cultura africana sino también entender que existe un quiebre con ese mundo dado por la diáspora forzada y la esclavitud. No se trata, por lo tanto, tan sólo de recuperar una cultura de origen, sino que también de apropiarse de una memoria traumática, de valorizar la cultura creada a partir de la diáspora y de reconocerse como parte del proceso histórico caribeño." (Oliva, E. 2010).

Como dice Pakman (2010) nuestra propia subjetividad como colectivo se está transformando para naturalizar la exclusión. No podemos decir que actualmente la identidad de todos los latinoamericanos sea creada de esta manera. Muchos habitantes de este continente han asumido un rol natural de colonos del siglo XXI, identificándose mucho más con el continente europeo o un país norteamericano creyendo haber nacido en el lugar equivocado. El mismo autor señala que la coercitividad de las opresiones se hace menos necesaria bajo un concepto de "control y domesticación", porque la conducta cotidiana de sujetos libres es la que mantiene y trasmite una idea que reproduce una micropolítica que categoriza normalidad o anormalidad, exclusión o inclusión. La clase alta haitiana ha desarrollado este aspecto, 
hablando casi exclusivamente francés, y no kreyol, el idioma nativo de los haitianos. Todas las escuelas de clase social alta hablan francés.

Hoy (como antes) las verdades más impuestas se han colado en nuestras casas, en nuestras familias, nuestros televisores, nuestros corazones. La identidad haitiana se mezcla con la extranjera y hoy existen nuevas formas de trasmitir la opresión.

Como nos explica Freire (1968) la generosidad que viene del opresor, y no del mismo pueblo para con el pueblo, es falsa, puesto que sigue imponiendo verdades. La cooperación internacional en Haití ha hecho de la generosidad, una virtud impuesta. Lo podemos ver en la creación del grupo de ayuda a Haití post terremoto, por gobiernos extranjeros, pero sin la participación de los mismos haitianos. Recordemos también el famoso caso de la Cruz Roja Estadounidense que gastó 500 millones de dólares en la construcción de 6 casas de emergencia con una intención inicial de construcción de 130.000 viviendas (Soreman, G. 2014).

"Debe enraizarse en la verdad y requiere un fundamento imaginario para ser efectivo, ya que es imposible gobernar sólo con la mentira y la opresión, sin tener en cuenta la intimidad personal. Este tipo de poder estaría simplificado en la familia, donde es idealmente efectivo un modelo de persuasión por el amor, sin la obligación de las leyes." (Pakman, M. 2010, p. 138).

Vemos en esta cita que el autor hace referencia a una verdad personal. Las verdades de algunos, entonces, se hacen las verdades de muchos. Las utopías, entonces, no son sino verdades propias de lo que para nosotros nos gustaría que fuera el mundo, y en la que muchas veces entran en nosotros ideas $\mathrm{u}$ otras verdades teñidas de poder.

La historia americana comienza con una imposición más evidente, comienza a la fuerza. Pero deriva en un proceso que se va sutilizando hacia lo que podemos denominar un eurocentrismo. No hace falta pensar en la época colonial para entender esto, sino que el mismo proceso de descolonización es, en parte, europeo, porque centra en ellos la importancia de seguir independizándonos, y no de retomar y pensar lo nuestro en conjunto. La herencia que nos trae la globalización nos lleva a entender procesos y valores unificados que dejan cada vez más afuera a aquellos que no entran dentro del matriz correcto de ser humano. La pobreza misma se ha globalizado y se han globalizado sus formas de intervenir en ella, cada vez apartándola más, dejándola más afuera de nuestras ciudades, trabajando desde el asistencialismo temeroso de contagiarse de algo. En educación a esto se le denominó GERM por sus siglas en inglés: Movimiento de Reforma Educacional Global, y fue un término acuñado por el autor Pasi Sahlberg en el 2010. Nuestras verdades generan cada vez más mentiras, cada vez más exclusiones de otros. GERM es la prueba de que cuánto más inclusión, más exclusión hay.

\section{Desde el "ser más" hacia la Educación Popular y la interculturalidad}

" [... Comprendimos] que nuestra miseria era riqueza para unos cuantos, que sobre los huesos y el polvo de nuestros antepasados y de nuestros hijos se construyó la casa de los poderosos, y que en esa casa no podía entrar nuestro paso, $y$ que la luz que la iluminaba se 
alimentaba de la oscuridad de los nuestros, y que la abundancia de su mesa se llenaba con el vacío de nuestros estómagos, y que sus lujos eran paridos por nuestra miseria, y que las fuerzas de sus techos y paredes se levantaron sobre la fragilidad de nuestros cuerpos, y que la salud que llenaba sus espacios venía de la muerte nuestra, y que la sabiduría que ahí vivida de nuestra ignorancia se nutría, que la paz que la cobijaba era guerra para nuestras gentes." (Dussel, E. 2007).

El ser más de Freire ${ }^{4}$ nos lleva a entender la identidad misma del oprimido y a lógica de la Educación Popular. Estos dos conceptos se nutren mutuamente puesto que la educación popular, como el ser más, da vuelta la pirámide del poder y entiende una educación construida desde los mismos protagonistas de la educación, y no tanto bajo lógicas de imposición de recetas estructuradas educativas, y políticas internacionales de educación, como ha pasado en gran parte en Haití.

La educación popular se puede definir de varias maneras. De hecho, no existe una definición oficial sobre educación popular, sino que la misma se fue construyendo a través de las prácticas y acciones concretas. El ideario fundamental de la educación popular se puede remontar hacia atrás en la historia latinoamericana desde Simón Rodriguez, o incluso antes si quisiéramos analizar más en profundidad la ideología de los pueblos originarios. Dussel (2007), transcribe el "Comunicado de la Comandancia General: Elecciones

\footnotetext{
${ }^{4}$ Podemos hacer un paralelismo con el concepto de Magis, utilizado por San Ignacio de Loyola. Para esto recomendamos el libro: Rodriguez Olaizola, JM. 2006. Ignacio de Loyola, nunca solo. Editorial San Pablo: Madrid.
}

Democráticas" del Ejército Zapatista de Liberación Nacional, y hace referencia indirecta a esto cuando habla de la organización de la democracia Maya.

"Si se apartaba su andar de lo que era razón de la gente, el corazón que mandaba debía cambiar por otro que obedeciera. Así nació nuestra fuerza en la montaña, el que manda obedece si es verdadero, el que obedece manda por el corazón común de los hombres y mujeres verdaderos. Fue nuestro camino siempre que la voluntad de los más se hiciera común en el corazón de hombres y mujeres de mando. Era esa voluntad mayoritaria el camino en el que debía andar el paso del que mandaba."

Podemos encontrar cierta definición de educación popular desde diversos puntos: su acción política, el contexto social donde trabaja, pero sobre todo nosotros optamos por la definición que alude a la capacidad transformadora de los protagonistas de la misma educación por sobre su propio contexto. Para Raúl Mejía la educación popular se define por "su intencionalidad transformadora, y la entendemos como un movimiento alternativo, enfrentado a las prácticas educativas tradicionales, que intenta promover una sociedad más democrática y más justa".

Al mismo tiempo la educación popular se puede definir por una práctica pedagógica del conflicto, para que este pase a ser un factor de crecimiento comunitario político-educativo. También incluye otros elementos fundamentales para este trabajo, como pueden ser: una opción ética del ser humano como gestor de su propia vida y en el contexto como constructor de su propia comunidad; un comienzo en la realidad social porque las prácticas educativas son re 
contextualizadas de acuerdo a los sujetos, grupos, lugares, instituciones; procesos de autoformación y de organización con el reconocimiento de las potencialidades propias de los protagonistas de la educación y del contexto donde está situada, junto con una investigaciónacción que se transforma en un proceso de conocimiento práctico-teórico; una conciencia de pertenencia continental lationamericana; y un empoderamiento de excluidos y desiguales que de-construyen estructuras de poder vigentes $y$ autoritarismos ya establecidos a través de lo que Pakman (2010) llamó (y ya hemos hecho referencia a esto) "control y domesticación". Steve Biko (1987) también hacía referencia a esto cuando hablaba de que el arma del opresor es el propio oprimido, y que el opresor triunfa cuando el mismo oprimido asume su falsa inferioridad.

En lo que refiere a este trabajo destacamos que una característica muy importante de la educación popular es que contiene una negociación cultural que centra las relaciones interculturales de manera que los encuentros de diversas posturas generan nuevas formas de trabajo contextualizado. En este sentido la interculturalidad pasa a ser una estrategia positiva para la deconstrucción de verdades impuestas y re pensar las relaciones de poder estructuradas.

Así es que nuestras verdades y utopías deben esforzarse cada vez más en dejar de ser verdades que excluyen mentiras para empezar a ser consecuencias de crecimiento comunitario, sacando el centro del poder que tiene mi verdad (por muy buena que parezca) y llevarlo hacia una lógica integradora del ser humano, de crecimiento colectivo. "Ya nadie educa a nadie, así como tampoco nadie se educa a sí mismo, los hombres educan en comunión, y el mundo es el mediador" (Freire, P. 1968).

Por supuesto que esto todavía sigue siendo una paradoja porque el mismo concepto de crecimiento comunitario es una verdad, y difiere de una persona a otra. Por eso algunas verdades excluyen a conciencia, asumiendo con orgullo que así lo hacen. Esto no nos quita la posibilidad de análisis y de asumir que algunas verdades llevan a la miseria más extrema, y a la misma muerte del ser humano.

Como ninguna verdad tiene valor en sí misma, ninguna verdad es superior a la otra. Por esto, nos vemos forzados a hacer un análisis comunitario y general del ser humano como especie. $\mathrm{Si}$ las consecuencias de estas utopías son esencialmente comunitarias debemos ir opuestos a lo que dice Galeano y creer que cuando caminamos, el horizonte efectivamente se acerca. Muchas ya lo han hecho. Expliquemos cómo ha funcionado esto en los últimos años en Haití.

Veamos entonces la experiencia del voluntario que va hacia Haití. Nos encontramos con una ardua paradoja: ¿Quién libera a quién? ¿Quién soy yo para liberar al otro? El voluntario viaja miles de kilómetros sólo para darse cuenta que lo que su pasaje costó (en general financiado por empresas multinacionales) podría haber pagado el trabajo de muchos otros en esta tierra. Muchos entran en una gran crisis. Si alguien dijo que hay voluntarios sin crisis, es porque algo están ocultando o porque quieren ocultar otras verdades.

"Nadie puede liberarse cuando domina a otro (...) Con el supuesto de que vamos a liberar a los otros (...) ni siquiera 
nosotros nos liberamos" (Bondy, S., en Dussel, 2007).

El caso haitiano, tanto por su historia como por su relevancia internacional ha generado grandes debates y es terreno de discusiones prácticas y teóricas sobre cómo actúa la globalización en nuestro tiempo, cuáles son las verdades universales que deben primar por sobre las otras y cómo los organismos internacionales como el Banco Mundial han sabido bajo lógicas asistencialistas y en primer aspecto de buenas intenciones, generar proyectos y políticas de desigualdad.

Como humanidad (y sobre todo como sociedad occidental) nos hemos atrevido a redactar y promover derechos universales, es decir, verdades y utopías redactadas por algunos para todos, desde el mismo momento del nacimiento y antes.

Es aquí cuando entra en juego la paradoja misma de los derechos universales, las políticas migratorias y las relaciones multiculturales. ¿Cómo promover y conservar el derecho a la diferencia estableciendo valores comunesuniversales, que en algún momento eran establecidos por una cierta territorialidad? Y al mismo tiempo ¿Quién decide estos valores universales y por qué? Las mismas preguntas que se realiza un voluntario o una ONG al ir a Haití, ¿Son mis ideas más válidas o superiores a las que ya existen aquí? ¿Tengo algo que aportar? ¿Tienen algo que aportarme a mí?

Incluso una de ellas debe de someterse a la otra. Es curioso que en Haití pasa un fenómeno opuesto al que pasa con los movimientos migratorios actuales. Si un grupo de refugiados (por ejemplo) entrara a otro territorio, debe de empezar a regirse por los valores y normas de este nuevo territorio con la esperanza de no perder algunos propios. En Haití la cooperación internacional ha ocupado el lugar de territorio al que se debe de adaptar Haití en su propio país.

Es así que volvemos a nuestra idea original: las verdades y las utopías en sí mismas no tienen ningún valor moral o ético, sino las consecuencias o las acciones que nos llevan a estas.

Analicemos nuevamente la idea de los derechos universales, por ejemplo, el derecho universal a la educación. De nada sirve que alguien declare que yo tengo derecho a la educación, eso no genera automáticamente que me soy investido de este derecho cual poder mágico y las condiciones en el mundo inmediatamente se tornan favorables para tener un desarrollo librepensante. Es más, la simple declaración del derecho a la educación ha movido a la humanidad hacia lugares muy opuestos: El Banco Mundial, bajo su manto de la superación de una pobreza económica, ha influido fuertemente en las políticas educativas latinoamericanas y haitianas con una lógica mercantil de la educación; la educación popular, con un referente fuerte en la pedagogía del oprimido de Paulo Freire (aunque con orígenes muy anteriores) promueve una lógica contextual de la educación y una ontología participativa de los oprimidos (Mejía, MR. 2006).

No podemos declarar que estas lógicas sean ni buenas o malas, ni asumir que tienen un valor ético, sino que podemos vemos ver y analizar sus consecuencias.

La lógica mercantil de la educación promueve la accesibilidad como una de sus banderas, aunque para que haya una 
mayor accesibilidad menos docentes deben deberán atender a más niños por un precio más bajo. Al mismo tiempo la lógica mercantil del Banco Mundial ha permitido penetrar en las zonas más pobres del mundo, entre ellas Haití, generando propuestas educativas donde no las hay. En Haití, por ejemplo, la misma cooperación internacional ha puesto escuelas donde no las había, aunque al mismo tiempo muchas de ellas han seguido la lógica de las recetas, verdades importadas de fuera, dejando de lado la participación comunitaria. La educación popular ha reforzado la participación y la pertinencia de esa misma educación en contextos de pobreza, aunque desde una lógica de deconstrucción de relaciones de poder, permitiendo emerger en competencias las zonas más pobres del mundo. Podemos ver que no hay una opción que no pueda sobrevivir sin la otra. Pero podemos ir de a poco analizando sus consecuencias para entender qué efecto tiene sobre el otro.

Por estas paradojas muchas ONG's que trabajan en Haití han tenido que replantear sus propuestas de trabajo hacia una postura de trabajo cooperativo saliendo del protagonismo inicial para reforzar el trabajo en conjunto con propuestas comunes con el contexto en donde trabajan.

Bajo esta situación algunas ONG's internacionales, la mayoría más chicas (como América Solidaria o Techo) sufrieron un cambio en general liderado por sus voluntarios en terreno. Este cambio radica en sus verdades, en su paradigma de trabajo, y demanda una necesaria adaptación que el mismo pueblo haitiano pedía, una relación más horizontal, que luego se empezó a llamar cooperación sur-sur ${ }^{5}$ ¿Cómo fue este proceso?

Cuando el voluntario se entera que va a ir a Haití, casi por lo general asume verdades que de a poco fueron entrando a nuestras casas y a nuestros corazones, se imagina algo que no se asemeja exactamente con la realidad con la que se va a encontrar. La imaginación es fundamental en desarrollo de verdades y exclusiones y esto es lo que vamos a ver. La diferencia entre un voluntario y el otro se encuentra después: en las estrategias de trabajo y de vínculo con las personas que se tenga, en el traspaso desde una postura globalizada a una contextual.

La historia del país en conjunto con lo que ya se declaraba sobre "el país más pobre de América", y el terremoto del 2010 normalizó varias verdades de las que muchas veces el voluntario, con muchas buenas intenciones, es parte de ellas.

La primera: un país destrozado y con cero recursos, casi caricaturesco, donde la gente es incapaz de tomar las riendas de su país. Es verdad que hay pocos recursos y hay mucha pobreza, pero eso no quiere decir nada. Muchos voluntarios se sorprenden por la calidad de vida a la que ellos mismos llegan y la enorme alegría con la que vive ese pueblo su vida.

La segunda: un mini súper héroe que vive dentro de nosotros y que va a Haití a salvar el mundo. Pero claro, no podemos olvidarnos que este mismo razonamiento lo tuvo Colón cuando pensó que sus verdades eran mejores que las de los pueblos que ya estaban en América.

\footnotetext{
${ }^{5}$ No quiero decir con esto que la cooperación sur-sur surge en Haití, sino que la exige desde su contexto.
} 
La tercera: después de percatarse de relatividad de sus ideas previas muchas veces se positiva toda la cultura del otro disminuyendo la nuestra a cero. De esta manera no existirá tampoco un encuentro real, y no apuntaremos nunca al constructivismo que deseamos. En otras palabras, sustituimos unas verdades por otras.

La cuarta: el voluntario cae necesariamente en una imagen que es percibida por los otros y de la que quiere correrse todo el tiempo. El voluntario carga con toda esa historia de invasiones que ya tiene la cultura y las heridas haitianas y que viene desde hace mucho tiempo y representa al invasor, al opresor y al que viene a hacer de su país lo que quiere. Muchas veces esto sigue siendo cierto, muchas ong's trabajan sin nunca hablar el idioma del país, nunca interesándose por la vida de los demás y viviendo en casas aisladas de la población, casi en burbujas exclusivas. Y por eso también esta imagen sigue normalizándose.

Pero los voluntarios ocupan un lugar del que no tienen ni idea que van a ocupar. Se les tira encima una historia de la cual se tienen que hacer cargo y no se sabe muy bien cómo. Y es aquí que se diferencia un voluntario del otro, o una ONG de la otra. "Representan a un sistema que va a dar o negar beneficios a través de su poder de diagnosticar, dada su posición en el sistema de salud y su relación con el sistema de discapacidad y beneficios sociales (...) en la práctica se le convierte en la cabeza visible de un sistema cuyas distinciones no son claras para el paciente-cliente (...) Ante este complejo dilema, los psicoterapeutas (voluntarios) tratan de crear espacios de autonomía de difícil mantenimiento dada la omnipresencia de la micropolítica de la discapacidad en la vida de las minorías discapacitadas". (Pakman, M. 2010, p. 63).

Por eso en este momento debemos comenzar un proceso intercultural y comunitario. Nos vemos casi forzados a esto ya que la historia de Haití, dibujada en los poros y la piel del mismo pueblo haitiano, lo demandará. Este proceso empieza por reconocernos a nosotros mismos como parte de este entramado de verdades impuestas. Los procesos de relación intercultural, entonces, ayudarán a despojarnos un poco más de estas para generar un proceso de empatía. La empatía es un elemento fundamental para las relaciones interculturales (Alsina, R. 1999). Y de nuevo podemos decir que mi verdad no es superior a la de nadie, y por eso el encuentro comunitario, mediado esta vez por las relaciones interculturales que generan empatía, es la forma de generar un encuentro de verdades. Nos encontramos en el punto en el que somos nosotros los liberados, y ocupamos al mismo tiempo el lugar de oprimidos de otras verdades. Sólo así podremos empezar un trabajo de igual a igual y en beneficio de la comunidad.

Podemos decir incluso que en una relación intercultural empática de, por ejemplo, dos personas, cada uno deberá salir un poco de su verdad (o de sus zonas de confort) para entrar cautelosamente en 
una nueva instancia de generación de ideas que nunca antes se habían creado ${ }^{6}$.

"Ahí radica la gran tarea humanista e histórica de los oprimidos: liberarse a sí mismos y liberar a los opresores. Estos, que oprimen, explotan y violentan en razón de su poder, no pueden tener en dicho poder la fuerza de la liberación de los oprimidos ni de sí mismos. Sólo el poder que renace de la debilidad de los oprimidos será lo suficientemente fuerte para liberar a ambos. Es por esto por lo que el poder de los opresores, cuando pretende suavizarse ante la debilidad de los oprimidos, no sólo se expresa, casi siempre, en una falsa generosidad, sino que jamás lo sobrepasa. Los opresores, falsamente generosos, tienen necesidad de que la situación de injusticia permanezca a fin de que su 'generosidad' continúe teniendo la posibilidad de realizarse. El 'orden' social injusto es la fuente generadora, permanente, de esta 'generosidad' que se nutre de la muerte, del desaliento y de la miseria". (Freire, P. 1968).

Esta gran cita de Paulo Freire nos expresa que si el opresor pretende suavizarse ante la debilidad del oprimido también genera vínculos de superioridad y opresión. Esto

\footnotetext{
6 En este punto haremos un paréntesis para sugerir que se reflexione sobre una frase muchas veces escuchada: "nada es nuevo, todo se repite". Sin la intención de imponer mi verdad por sobre otras ideas, debo decir que las circunstancias y variables que atraviesan al desarrollo de cada persona y que hacen al mismo tiempo que cada persona sea única e irrepetible, es lo que hace posible que en nuevas comunidades se generen nuevas ideas sin la necesidad de ser como ninguna otra en el mundo. El contexto es la que las diferencia.
}

nos lleva directamente a todo el proceso histórico que ha vivido Haití durante muchos años, y cómo la cooperación internacional puede seguir perpetuando en suavizar con falsa generosidad, pero sin generar procesos que la dejen liberarse de las grandes verdades que quieren imponer.

"Se ha obtenido una aproximación a la verdadera idiosincrasia del caribeño al incorporar el aporte de millones de hombres que sirvieron como fuerza de trabajo esclava en la producción de azúcar, café, añil, algodón, etcétera." (Portuondo Zúñiga, O. 2014, p. 94).

Como ya hemos visto, en el contexto haitiano, la comunidad internacional se ha visto casi forzada a trabajar con la educación popular y con la interculturalidad como estrategia de la misma, siendo esta la alternativa para que se trabaje en conjunto para la transformación de Haití y del continente. Estas relaciones interculturales implican para el que viene de fuera, asumir una posición que muchas veces no busca, pero que busca romper constantemente con estereotipos de extranjero poderoso, y promover el trabajo comunitario a la par. Estos procesos de confianza tardan muchas veces meses, e implica el cambio del discurso de ayuda al otro, al de ayuda mutua, y un aprendizaje del idioma materno del país, el creole. Implica al mismo tiempo.

Una de las características más fuertes de un proceso de educación globalizada y de la imposición de unas verdades por sobre otras, es la homogenización de los idiomas, quedando muchas veces (y no sólo en Haití) los idiomas maternos fuera de la educación misma. 
"No hablar la lengua materna. Habitar unas sonoridades, unas lógicas separadas de la memoria nocturna del cuerpo, del sueño agridulce de la infancia. Llevar en el propio cuerpo interior una especie de panteón secreto, o un niño disimulado amado e inútil-: la lengua de antes que se marchita sin abandonarte nunca. [...] Así, entre dos lenguas, tu elemento es el silencio. De tanto decirse de diferentes modos, todos igualmente triviales, todos igualmente aproximados, al final deja de decirse. [...] Nada que decir, nada, nadie en el horizonte. No decir nada, nada hay que decir, nada es decible. Al principio fue una guerra fría contra los del nuevo idioma, deseado y rechazante: luego la nueva lengua te recubrió, como una marea lenta de aguas muertas. Un silencio que no es el de la cólera que atropella las palabras al borde la idea y de la boca, sino el silencio que vacía la mente y colma el cerebro de agobio, como la mirada de las mujeres tristes enroscada en alguna inexistente eternidad". (Kristeva, J. 1988)

\section{Conclusiones}

No importa la fuerza con que se imponga nunca habrá una verdad superior a la otra. Por supuesto que puede haber formas de control, pero eso no genera valóricamente una superioridad de una por sobre la otra. A pesar de que no haya superioridad de una verdad sobre las otras, el énfasis extremo en querer imponer una sobre otra genera necesariamente exclusiones de algunos. La educación representa la reproducción y, al mismo tiempo, una alternativa de dichas verdades impuestas. Por eso, ante la imposibilidad de tener verdades superiores a otras, el análisis comunitario debe de ser primordial, y para ello la educación popular se ha valido de la estrategia intercultural.
Por sus características históricas, el territorio haitiano responde a este razonamiento y genera la necesidad del trabajo en educación popular con la interculturalidad como estrategia de encuentro y creación de nuevas formas participativas de trabajo. Esto no quiere decir que hoy en día la cooperación internacional no responda muchas veces a patrones importados de superación de la pobreza y trabajo en educación, lo cual genera nuevamente verdades que son falsamente superiores a las que propone el mismo pueblo haitiano. La historia y la cooperación internacional actual se unen para generar una lógica de "ser más" en el mismo pueblo haitiano, y por tanto la educación popular, surge con fuerza con una estrategia necesaria de interculturalidad.

La interculturalidad es, entonces, una estrategia de la educación popular que nos servirá para trabajar en los nuevos vínculos de confianza entre las organizaciones que vienen de fuera y los profesores haitianos que ya se encuentran trabajando ahí. Al mismo tiempo esto establecerá relaciones horizontales de trabajo que no imponen formas, sino que construyen en conjunto.

La posición comunitaria, con estrategias interculturales nos mueven a pensar no en un territorio desvalido por su pobreza, sino en un continente común donde todos nos construimos entre todos y todos nos educamos entre todos.

\section{Referencias}

Alsina, MR (1999). Comunicación Intercultural. Barcelona: Antrhopos.

Astaburuaga, F. Iglesias, N. Gómez, Mp. (2015). Programa Primera Infancia 2014 - 2015. América Solidaria Haití. 
Barzola, Paola, et Al. (2012). Razón moderna $y$ otredad. La interculturalidad como respuesta. Ciencia, Docencia y Tecnología, XXIIIMayo-Sin mes, 111-135.

Biko, S. (1987) I write what $i$ like. Oxford: Aelred Stubbs C.R.

Barrios, Y (2000). Educación Popular y Promoción Social. Propuesta de Fe y Alegría. Caracas: Federación Internacional de Fe y Alegría.

Bellegrade, P (2004). Haití. La ciudadela vulnerada. Oriente: Santiago de Cuba.

Carrasco, I (2015). Interculturalidad, ¿qué es? ¿qué puede ser? ¿para qué usarla? (s/d)

De Souza Santos, B (2014). Epistemologías del sur. Akal:

Federación Internacional de Fe y Alegría (2004). La identidad de Fe y Alegría. Colombia: Federación Internacional de Fe y Alegría.

Fanon, F.(1961). Los condenados de la tierra. París: Fondo de cultura económica.

Freire, P (1968). Pedagogía del oprimido. Buenos Aires: Siglo XXI.

Freire, P. Antunez, F. (1986). Hacia una pedagogía de la pregunta. Buenos Aires: Siglo XXI.

Giaccaglia, MA et. Al (2012). Razón moderna y otredad. La interculturalidad como respuesta. Ciencia, docencia y tecnología. XXIII Mayo, pp. 111-135.
Kristeva, Julia. 1988. Extranjeros para nosotros mismos. Barcelona: Hurope

Kuhn, T. (1962). La estructura de las revoluciones científicas. México: Fondo de Cultura Económica.

Mejía, MR (2006). Educación (es) en la(s) globalización(es) I. Entre el pensamiento único y la nueva crítica. Bogotá: Ediciones Desde Abajo.

Oliva, E. Stecher, L., Zapata, C. (2010). Aimé Césaire desde América Latina. Diálogos con el poeta de la negritud. Santiago de Chile: Universidad de Chile, CECLA.

Pakman, M (2010). Palabras que permanecen, palabras por venir. Micropolítica y poética en psicoterapia. Barcelona: Gedisa Editorial.

Palacios Díaz, A. (2005) La escuela de Frankfurt: el destino trágico de la razón. Universidad Autónoma de México: Revista del Tiempo, Abril 2005 .

Portuondo Zúñiga, O (2014). Caribe, raza e identidad. La Habana: UNIÓN.

Sales, A. (2007). Diversidad en el ámbito escolar: por una educación intercultural. En Quaderns Digitals: "Congreso Internacional de Orientación Educativa y Profesional”. Universitat Jaume I de Castelló.

Soreman, G. (2014). El corazón americano. $\mathrm{Ni}$ el Estado, ni el mercado: la opción filantrópica. Editorial Debate: s/d. 
Todorov, T (1986). El cruzamiento de las

Núm. 43. pp. 5-24 culturas. París: Communications. 